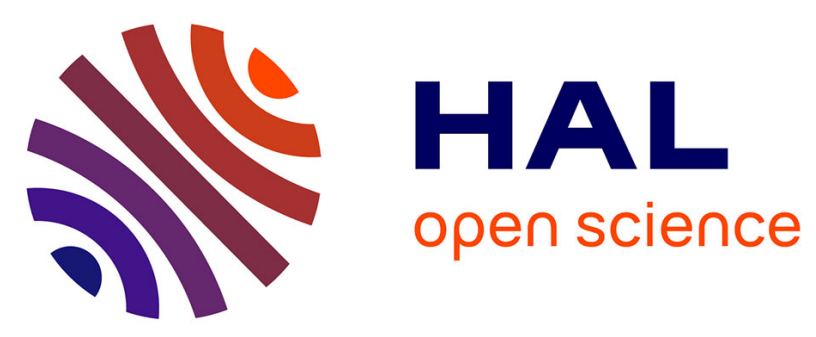

\title{
Digital Manufacturing in Smart Manufacturing Systems: Contribution, Barriers, and Future Directions
}

\author{
Sangsu Choi, Chanmo Jun, Wen Bin Zhao, Sang Do Noh
}

\section{To cite this version:}

Sangsu Choi, Chanmo Jun, Wen Bin Zhao, Sang Do Noh. Digital Manufacturing in Smart Manufacturing Systems: Contribution, Barriers, and Future Directions. IFIP International Conference on Advances in Production Management Systems (APMS), Sep 2015, Tokyo, Japan. pp.21-29, 10.1007/9783-319-22759-7_3. hal-01431114

\author{
HAL Id: hal-01431114 \\ https://hal.inria.fr/hal-01431114
}

Submitted on 10 Jan 2017

HAL is a multi-disciplinary open access archive for the deposit and dissemination of scientific research documents, whether they are published or not. The documents may come from teaching and research institutions in France or abroad, or from public or private research centers.
L'archive ouverte pluridisciplinaire $\mathbf{H A L}$, est destinée au dépôt et à la diffusion de documents scientifiques de niveau recherche, publiés ou non, émanant des établissements d'enseignement et de recherche français ou étrangers, des laboratoires publics ou privés. 


\title{
Digital Manufacturing in Smart Manufacturing Systems: Contribution, Barriers, and Future Directions
}

\author{
SangSu Choi, Chanmo Jun, Wen Bin Zhao, Sang Do Noh \\ Department of Systems Management Engineering, Sungkyunkwan \\ University \\ 300 Cheoncheon-dong, Jangan-gu, Suwon, Gyeonggi-do 440-746, \\ Republic of Korea \\ \{choiss, jchm99, wenbin86, sdnoh\}@skku.edu
}

\begin{abstract}
Today, smart manufacturing systems (SMS) are being developed to improve manufacturing competitiveness. Digital manufacturing (DM) is a technology that supports the carrying-out of tasks and decision-making based on digital models and simulation in a virtual environment, without physical prototypes or experiments. A DM system helps in the design and redesign and analysis of a factory, sustainably and efficiently, to optimize its performance in an SMS. In this paper, the contributions of DM systems in SMS and the application barriers of DM systems are described. A real case that has been developed to overcome the barriers is introduced. Finally, future directions of DM systems in SMS are discussed.
\end{abstract}

Keywords: cyber-physical system, virtual manufacturing, factory performance optimization, modelling and simulation

\section{Introduction}

Leading research institutes and global companies are developing and implementing smart manufacturing systems (SMS) to improve manufacturing competitiveness [1, 2]. Digital manufacturing (DM) is a technology that supports the carrying-out of tasks and decision-making based on digital models and simulation in a virtual environment, without physical prototypes or experiments [3].

A DM system is based on computer-aided design (CAD), simulation, and an information-sharing model. It makes use of legacy systems such as product lifecycle management (PLM), enterprise resource planning (ERP), manufacturing execution systems (MES) and supply chain management (SCM) [3, 4]. DM is an essential system in the design, redesign, and analysis of a factory in SMS [5, 6]. DM is being implemented and developed into various manufacturing industries.

This paper is structured as follows. In Section 2, the contributions of DM in SMS are explained. In Section 3, application barriers of DM are described. A case that has been developed to overcome the barriers is introduced in Section 4. Finally, future directions of DM in SMS are discussed. 


\section{Contribution of DM in SMS}

SMS connects all manufacturing elements such as procurement, production, product, logistics and service. It controls the process of production by a cyber-physical system (CPS) [7] as a unified environment. CPS enables not only the exchange of all necessary information for the manufacture of optimized products, but also the control of the entire production process in the factory, based on the "internet of things" (IoT) [8]. DM in SMS is located as a virtual factory for the manufacture of products in a cyber-area, as shown in Figure 1. DM in a SCOR model [9] covers the Plan as it is related to the Make process, and those parts of the Source, Delivery and Return processes that are connected with Make.

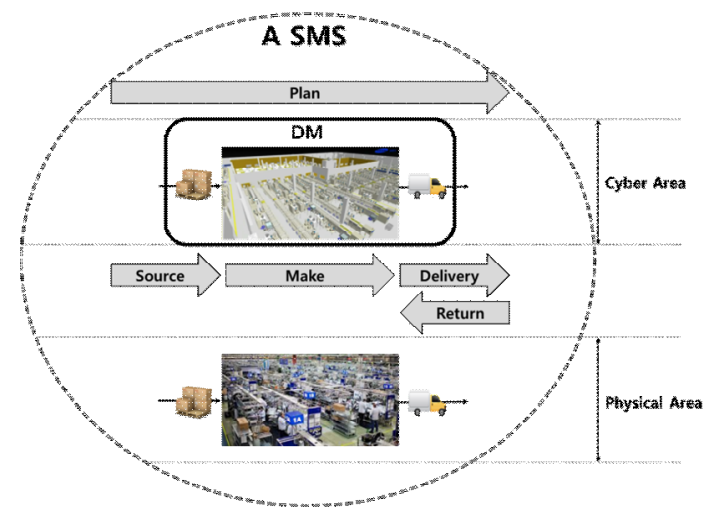

Figure 1. DM coverage in a SMS

There are three types of DM: design-centered, production-centered, and controlcentered, according to the application field and the purpose, as shown in Figure 2 [3].

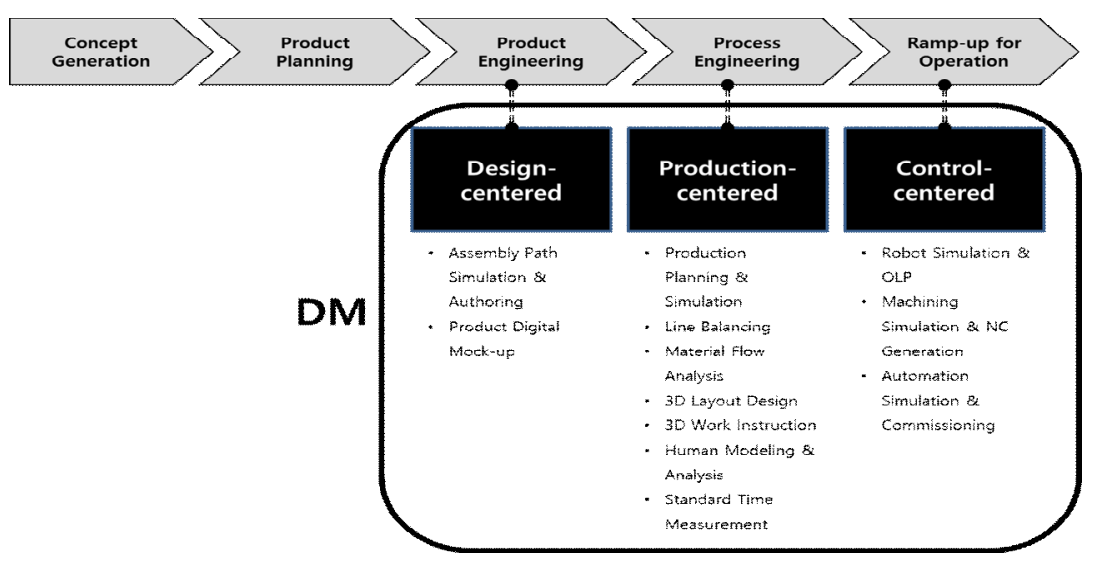

Figure 2. Functional classification of DM 
Design-centered DM has functions of assembly path simulation and authoring, and product digital mock-up, for support of design and engineering tasks $[10,11]$. Production-centered DM supports manufacturing preparation tasks related to the functions of production planning and simulation, line balancing, material flow analysis, 3D layout design, work instructions, human modelling and analysis, and standard time measurement $[10,11]$. Control-centered DM focuses on monitoring and controlling by direct interface with production systems and machines on the shop floor. It includes functions of robot simulation and off-line programming (OLP), machining simulation and numerical control (NC), and automation simulation and commissioning $[10,11]$.

\section{Barriers of DM application}

We have built over 40 virtual factories based on DM for automotive, electronics, machinery, and shipbuilding companies in Korea for 15 years. The barriers were analysed based on the experiences. [15, 27, 28, 29]

\subsection{The Approach based on Functions of DM system (view of DM vendor)}

Consultants and engineers in DM vendors [10, 11] have an approach based on system functions. At the time of meeting with the manufacturing company, DM vendors provide solutions by the mapping of system functions according to the customer's requirements. DM vendors usually believe that all requirements will be satisfied and functions supported because they are offering powerful systems.

However, the functions overlap and integration problems often occur because the manufacturing company is already using heterogeneous software packages. In addition, manufacturers will often have employees whose ways of working are based on their own experience and existing methods, and without the use of software packages. They tend to resist the introduction of new software packages and systems. This resistance is higher in engineers than it is in managers.

\subsection{The Approach based on Tasks of Optimizing Factory Performance (View of Manufacturing company)}

Tasks in the factory are complex and have variability [12]. Manufacturing companies often have trouble in explaining accurately and clearly their current problems and their requirements for system development, due to various reasons such as confidential data or unawareness. But a clear analysis of requirements at each manufacturing level, from individual machine to the factory as a whole, is essential for project success.

Then, performance measures and the correlations have to be defined based on the analysis. The person in charge at each manufacturing level tends to care only about his or her particular area of work. Thus, it can be difficult to define performance measures and the correlation analysis for an entire factory performance optimization. 
Many researches have been carried out on factory performance measures [12, 13, 14]. However, there is a shortage of correlations analyses. In order to develop a DM system successfully, a definition of performance measures and a correlations analysis for the entire factory are necessary.

\subsection{Barriers between Two Approaches}

A manufacturing company can develop an over-optimistic view of the effect of a DM system that has fancy 3D visualization. Sometimes, they believe that all the problems in the factory will be identified and solved without any efforts, simply by purchasing such a DM system. Undirected or vague development without determination of factory performance measures and elimination of engineers' resistance can lead to a negative return on investment (ROI). Specific and clear communication, informed decision-making, and role performance between the DM vendor and the manufacturing company lead to success in system development.

Three important factors are summarized which will eliminate the barriers between two approaches as mentioned earlier:

- clear definition of factory performance assurance, performance measures, and their correlation;

- mapping between derived performance measures and functions of DM systems;

- data exchange and integration between heterogeneous software packages and systems (not only heterogeneous DM systems but also other related systems such as PLM, ERP, SCM, MES).

Solicitude and collaboration between DM vendors and manufacturing companies is most important, and is achieved through an understanding of the differences between them in areas such as knowledge, terms, and culture.

\section{Case Study}

In this Section, a real published case is introduced, in the light of the three important factors mentioned above.

e-FEED [5] is a system to comprehensively design, redesign, and analyse manufacturing processes and lines in the factory. e-FEED serves as a hub that provides knowledge and a standardized engineering process. It enables diverse factory development, with engineers and managers able to access the system simultaneously and make decisions through collaboration [5].

The factory design and improvement (FDI) process in the manufacturing company was analysed as the first priority in developing e-FEED. FDI has four steps: Requirement, Basic Design, Detailed Design and Test, as shown in Table 1 [6]. 
FDI is a complex process because of the need to determine the manufacturing method, equipment, processes and lines while considering the overall product lifecycle related to the product plan, design, and manufacturing. By analysing FDI using IDEF0 as shown in Figure 3, performance measures and the correlations were derived and the mapping of DM functions was carried out.

\begin{tabular}{|c|l|}
\hline Step & \multicolumn{1}{c|}{ Description } \\
\hline Requirement & $\begin{array}{l}\text { The customer's needs are investigated. General plans relating to } \\
\text { infrastructure, environment, budget, sales, production and schedule are } \\
\text { established. }\end{array}$ \\
\hline Basic Design & $\begin{array}{l}\text { After the production target is set, capacity, equipment and human } \\
\text { resources are estimated. The layout is designed briefly as well. Then a } \\
\text { more suitable production system is developed. }\end{array}$ \\
\hline Detailed Design & $\begin{array}{l}\text { Equipment and inspection machines are designed by analysing } \\
\text { manufacturing methods and processes. The material flow between } \\
\text { each process, each floor and each factory is designed by referring to } \\
\text { the estimated capacity in the basic design step. Material handling such } \\
\text { as loading and unloading, transportation, and storage are developed as } \\
\text { well. The final layout is determined on the basis of the modules, } \\
\text { processes, lines, and material flow design. }\end{array}$ \\
\hline Test & $\begin{array}{l}\text { The manufactured equipment is inspected and the real processes and } \\
\text { manufacturing lines are set up. Once arranged on the shop floor, the } \\
\text { layout, material handling and material flow are verified. Finally, all } \\
\text { processes are standardized under optimum conditions. }\end{array}$ \\
\hline
\end{tabular}

Table 1. Factory Design and Improvement [6]

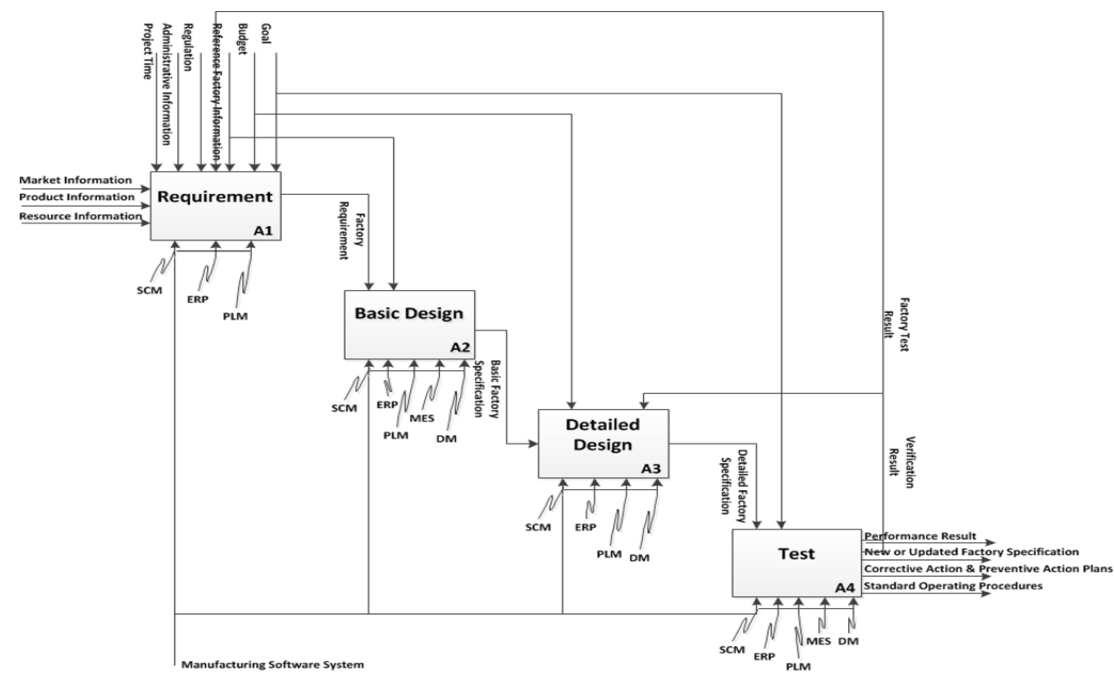

Figure 3. FDI Activity Modelling by IDEF0 [15] 
e-FEED consists of an advanced factory designer to design the layout easily, a database or library of equipment, processes and lines, and a XML schema [5] to enable an automatic interface between heterogeneous engineering software packages. Such a factory layout can be designed and changed easily. The simulation is run automatically by e-FEED, as shown in Figure 4. [5]
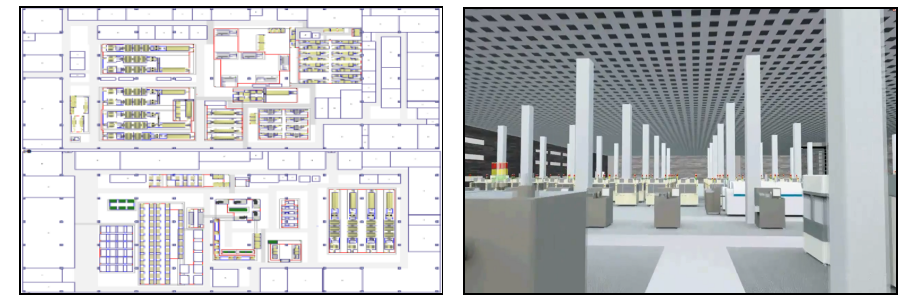

Figure 4. Layout Design and 3D Design Review [5]

The XML schema contains the Product, Process, Resource and Plant information as shown in Figure $5[16,17]$. The schema also has smart-supports rule data for design error verification and object relation information [5]. It was based on the PLM Services 2.0 [18] defined by the Object Management Group for PLM data exchange considering the extensibility, and included the scoring model and the result model for the integrated decision-making result report.

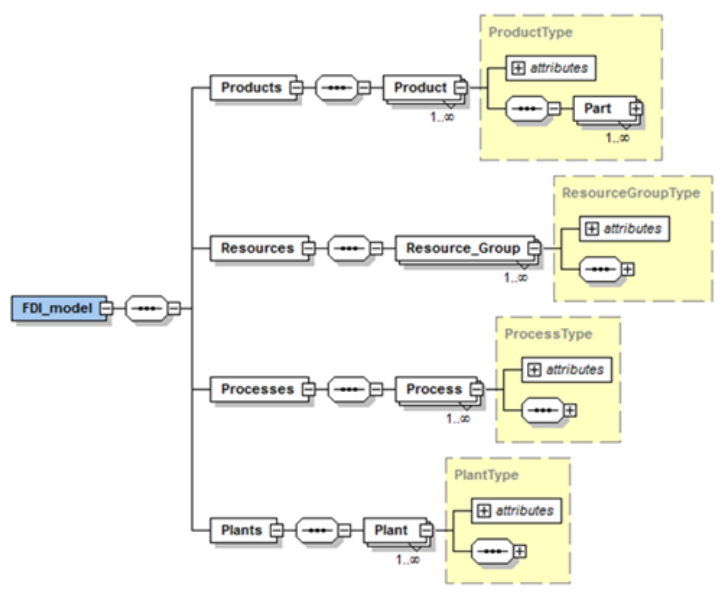

Figure 5. XML schema structure

The schema-based automatic interfaces between heterogeneous software tools to design, redesign, and analyze manufacturing processes were developed. Figure 6 shows software tools that the target company uses. If there are no ways such as application programming interface (API) or scripts in the software tools in order to exchange data, the task is carried out manually by the persons in charge. 


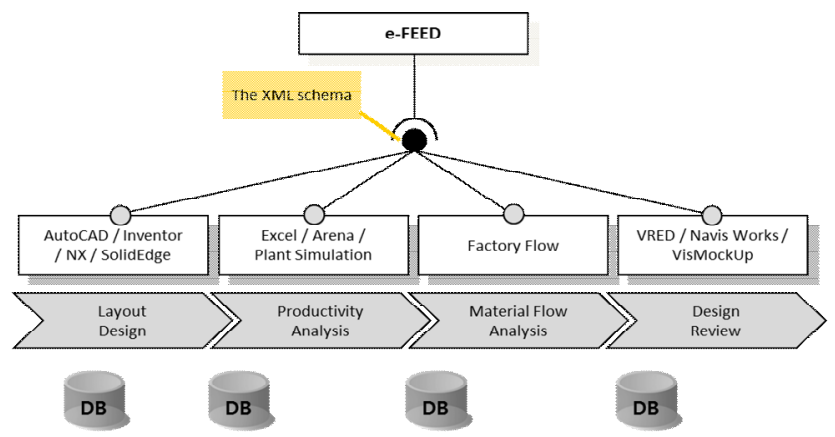

Figure 6. XML schema based Interface between heterogeneous software tools

Projects for new factory development and improvement of existing factories were carried out based on e-FEED. Work time for a new factory layout design was reduced from six weeks to 1.5 weeks, and improvement work on an existing factory that previously took four weeks can be carried out within one week [5]. Particularly timeconsuming tasks for factory performance optimizing such as data collection, creation of a simulation model and documentation are improved innovatively. The expected maintenance costs to operate the system are reduced as well. Above all, existing work processes that depend on a few experts are eliminated.

\section{$5 \quad$ Future Directions}

This paper explained the contributions of DM to SMS, and barriers encountered when DM is introduced at a manufacturing company. And a real case that tries to solve current problems between DM vendors and manufacturing companies is described. In order to develop a comprehensive system, FDI as an activity model is proposed and an XML schema is developed based on FDI. Tasks of DM development and factory performance optimizing are highly reliant on experts. FDI and the schema help to develop functional mapping of DM and the key performance measures at each manufacturing level, from individual machine to the factory as a whole, instead of experts. FDI is being extended and improved to support not only more specific works in the factory but also various industries. Interfaces to connect various software packages and systems that are already in use in the real company are incorporated into the schema as well.

As mentioned before, tasks in the factory are complex and have variability. Research into performance measures and the correlations between each manufacturing level in the factory have to be carried out actively. Standard reference models and data schemas are required for DM system development. A standard can dramatically reduce the trials and errors of system development. Moreover, once continuous factory design and analysis are executed and optimized, factory performance can be 
maintained stably and according to a standard. Training in such functions as factory performance, DM functions and project leadership is consistently required.

The future DM system will be improved into the realistic system $[19,20]$ by adopting virtual reality technology. In addition, control-centered DM connected to the shop floor will be implemented much more widely [21]. For this, an interface between a DM reference model and MTConnect [22] can be considered. The reference model has to be developed with regard to flexible interfaces with reference models of ERP, SCM, PLM and MES in SMS, such as SCOR [9], DCOR [23], MESA [24] and ISA95/88 [25, 26].

\section{References}

1. Bauernhansl, T., (2013), "Industry 4.0: Challenges and limitations in the production. Keynote", AT Kearney Factory of the year.

2. Smart Manufacturing, [Online] Available: http://smartmanufacturing.com/what/ [Accessed: 16-Feb-2015].

3. Noh, S.D., (2006), "CAD, Digital Virtual Manufacturing, and PLM”, Sigma Press, Seoul.

4. Kulvatunyou, B., Ivezic, N., Wysk, R. A., \& Jones, A. (2003), "Integrated product and process data for business to business collaboration", AI EDAM: Artificial Intelligence for Engineering Design, Analysis and Manufacturing, Vol.17, No.3, pp.253-270.

5. Choi, S. S. et al., (2014), "The integrated design and analysis of manufacturing line (I) Digital Virtual Manufacturing based on Automated Modeling \& Simulation System", Transactions of Society of CAD/CAM engineers, Vol. 19, No.2, pp.138-147.

6. Choi, S. S. et al., (2014), "The integrated design and analysis system of manufacturing line (II) - Continuous Design, Analysis and Optimization through Digital Virtual Manufacturing, Transactions of Society of CAD/CAM engineers, Vol. 19, No. 2, pp.148156.

7. Baheti, R., \& Gill, H., (2011), "Cyber-physical systems", The impact of control technology, pp.161-166.

8. Gubbi, J., Buyya, R., Marusic, S., \& Palaniswami, M., (2013), "Internet of Things (IoT): A vision, architectural elements, and future directions", Future Generation Computer Systems, Vol. 29, No. 7, pp1645-1660.

9. APICS Supply Chain Council, (2014), "Supply Chain Operations Reference Model Version 11.0".

10. Siemens Digital Manufacturing, [Online] Available [Accessed: 16-Feb-2015]:

http://www.plm.automation.siemens.com/en_us/plm/digital-manufacturing.shtml 11. Dassault Delmia, [Online] Available [Accessed: 16-Feb-2015]: http://www.3ds.com/products-services/delmia/portfolio/delmia-v6/overview/ 12. Ignizio, J. P., (2009), "Optimizing factory performance: Cost-Effective Ways to Achieve Significant and Sustainable Improvement", McGrawHill, New York.

13. Hon, K. K. B., (2005), "Performance and evaluation of manufacturing systems", CIRP Annals - Manufacturing Technology, Vol. 54, No. 2, pp.139-154. 
14. Neely, A., Gregory, M., \& Platts, K., (1995), "Performance measurement system design: a literature review and research agenda", International journal of operations \& production management, Vol. 15, No. 4, pp.80-116.

15. Choi, S. S., Kim, B. H., Noh, S. D., (2015), "A Diagnosis and Evaluation Method for Strategic Planning and Systematic Design of a Virtual Factory in Smart Manufacturing Systems, International Journal of Precision Engineering and Manufacturing", Vol. 16, No. 6, pp.1107-1115.

16. Yoon, T. H., Choi, S. S., Noh, S. D., (2007), "A PLM integrator for integrate product information management using commercial PDM systems", International Conference on Product Lifecycle Management, Milano, Italy.

17. Choi, S. S., Yoon, T. H., Noh, S. D., (2010), "XML-based neutral file and PLM integrator for PPR information exchange between heterogeneous PLM systems", International Journal of Computer Integrated Manufacturing, Vol. 23, No.3, pp.216-228.

18. PLM Services, [Online] Available: http://www.omg.org/spec/PLM/ [Accessed: 16Feb-2015]

19. Choi S. S., Jo H. J., Lee J. Y., Noh S. D., (2010), "A Rule-based System for the Automated Creation of VR Data for Virtual Plant Review", Concurrent Engineering, Vol. 18, No. 3, pp.165-183.

20. Choi S. S., Jo H. J., Boehm S., Noh S. D., (2010), "ONESVIEW: An Integrated System for One-Stop Virtual Design Review", Concurrent Engineering, Vol. 18, No. 1, pp.75-91.

21. Kulvatunyou, B., \& Wysk, R. A. (2001), "Computer-aided manufacturing simulation (CAMS) generation for interactive analysis: concepts, techniques, and issues". In Proceedings of the 33nd conference on Winter simulation. IEEE Computer Society. pp. 968-976.

22. MTConnect, (2008), [Online] Available: www.mtconnect.org [Accessed: 16-Feb2015].

23. APICS Supply Chain Council, (2006), "Design chain operations reference-model (DCOR)".

24. MESA International, (2014), “2013-2014 Manufacturing Metrics that Really Matter Summary Report".

25. ANSI/ISA-95.00.01-2000, Enterprise-Control System Integration Part 1: Models and Terminology

26. ANSI/ISA-88.00.01-2010 Batch Control Part 1: Models and Terminology.

27. Noh, S. D., Lee, C. H., Hahn, H. S., (2001), "Virtual Manufacturing for an Automotive Company (I)-Workflow Analysis and Strategic Planning of Manufacturing Preparation Activities", IE interfaces, Vol.14, No.2, pp.120-126.

28. Noh, S. D., Hong, S. W., Kim, D. Y., Sohn, C. Y., Hahn, H. S., (2001), "Virtual Manufacturing for an Automotive Company (II)-Constuction and Operation of a Virtual Body Shop", IE interfaces, Vol.14, No.2, pp.127-133.

29. Noh, S. D., Kim, D. Y., \& Park, Y. J., (2002), "Virtual Manufacturing for an Automotive Company (III)-Construction and Operation of a Virtual Paint Shop", IE interfaces, Vol.15, No.4, pp.356-363. 